\title{
Foreign aid and oil taxes: helping the poor in oil-rich countries
}

\section{Journal Article}

\section{Author(s):}

Berlinschi, Ruxanda; Daubanes, Julien

Publication date:

2012-06

Permanent link:

https://doi.org/10.3929/ethz-b-000413368

Rights / license:

In Copyright - Non-Commercial Use Permitted

Originally published in:

Environment and Development Economics 17(3), https://doi.org/10.1017/S1355770X12000022 


\title{
Foreign aid and oil taxes: helping the poor in oil-rich countries
}

\author{
RUXANDA BERLINSCHI \\ LICOS, Centre for Institutions and Economic Performance, Catholic \\ University of Leuven, Belgium. Email: ruxanda.berlinschi@econ.kuleuven.be
}

\author{
JULIEN DAUBANES \\ CER-ETH at ETHZ, Swiss Federal Institute of Technology Zurich, \\ Zürichbergstrasse 18, 8092 Zurich, Switzerland. Tel: +41 446322427. \\ Fax: +41 4463213 62. Email: jdaubanes@ethz.ch
}

Submitted October 29, 2010; revised September 4, 2011; accepted December 27, 2011; first published online March 27, 2012

\begin{abstract}
This paper proposes a theoretical analysis of the joint impact of foreign aid and oil taxes on the revenues of a rich oil importing country (North) and a two-class, oil exporting country (South). Without coordination, oil taxes are strictly higher in the North and the global allocation of oil is inefficient. Moreover, oil taxes in the North extract some of the South's oil rents, undoing the revenue transfers from foreign aid. We show that a policy coordination mechanism reduces inefficiencies and improves global welfare.
\end{abstract}

\section{Introduction}

Among the hottest policy issues currently discussed by global leaders in national legislations and international summits, foreign aid and oil taxation occupy a fairly important place. Persistent revenue discrepancies between high- and low-income countries sustain a demand for higher international redistribution through foreign aid. Important budget deficits faced by many high-income countries in the wake of the global economic crisis, as well as environmental concerns, are likely to lead to tax increases, in particular, taxes on oil products. These taxes affect the revenues of oil

This paper has benefited from comments by Yann Bramoullé, Christian Gollier, Patrick Gonzalez, Yolande Hiriart, Christian Kiedaish, Bruno Lanz, Pepita Miquel-Florensa, Andrew V. Perry, Gilles Saint-Paul, Sjak Smulders, Stéphane Straub and Cees Withagen, as well as by participants at the SURED 2008 conference, the Frontiers in Environmental Economics and Natural Resources Management TSE-AFSE conference, the 23rd Annual Congress of the EEA, the Economics seminar at the University of Geneva and the Matuszewski seminar at Laval University. Particular thanks go to Jean-Paul Azam and André Grimaud, and to two anonymous referees. 
exporting countries, some of which are low-income countries and recipients of foreign aid. The joint impact of aid and oil taxes on the revenues of both developed and developing countries needs to be understood and taken into account by policy makers in order to avoid inefficiencies resulting from policies offsetting the effects of each other. This paper analyzes the interaction of oil-rich and oil-poor countries via oil taxation and foreign aid policies and shows that an inefficiency arises from lack of coordination.

Industrialized countries collect considerable fiscal revenues by highly taxing oil products. The part consisting of taxes in the final price of a barrel was around 45 per cent in the G7 countries in 2007 (OPEC, 2008). These fiscal revenues represent 6.5 per cent of governments' earnings in the EU15 and 6 per cent in the OECD (International Energy Agency, 2001). However, these taxes capture a part of oil producing countries' rents. According to the Organization of the Petroleum Exporting Countries (OPEC), G7's fiscal revenues from oil products taxation between 2003 and 2007, US\$ 2,585 billion, exceeded oil producers' US\$ 2,539 billion revenues (OPEC, 2008). These figures suggest, for example, that during this period the G7 captured around US\$ 15 billion per year from the oil revenues of a country such as Nigeria, which produces 3 per cent of the oil consumed in the world. ${ }^{1}$

Many oil producers are low- or middle-income countries with important inequality levels. The average per capita Gross National Income (GNI) in the 19 countries with the largest crude oil reserves per capita was less than US\$ 5,800 in 2005 (PennWell Corporation, 2004; World Bank, 2010). In these countries, oil rents often benefit a small, powerful group, while the rest of the population remains poor. In Nigeria, for example, 70 per cent of the population live on less than one dollar a day. In 2006, this country received nearly US\$ 10 billion of foreign aid from the G7 (OECD, 2010). This amount is comparable with our estimation of US\$ 15 billion captured by the G7 from Nigeria through oil taxes. In the same year, the G7 disbursed US\$ 114 million to Algeria, US\$ 94 million to Ecuador, US\$ 48 million to Iran and US\$ 25 million to Venezuela (OECD, 2010).

Oil taxes are very low or even negative in low-income oil producing countries. For example, in Nigeria, Algeria, Iran and Venezuela, oil is subsidized. The gap in the oil tax rates between developed oil consuming countries and developing oil producing countries is statistically significant (Bacon, 2001).

The gap in oil tax rates between high-income oil consuming countries and low-income oil producing countries leads to inefficiencies in the global allocation of oil. When the final price of oil differs across regions, oil is not used where it is most productive.

The situation depicted above suggests a lack of coordination between rich oil consuming countries and poor oil producing countries. High oil taxes in rich countries distort the allocation of oil and take back through fiscal revenues some of the foreign aid transfers to those poor countries.

1 This estimation is based on the assumption that the share of Nigerian oil in the consumption of the G7 countries is the same as its share in world consumption, i.e., 3 per cent. 
This paper proposes a theoretical framework capturing the stylized facts described above and suggests a welfare improving policy coordination mechanism. The theoretical framework is based on standard assumptions borrowed from development and resource economics literatures.

Development economists have extensively studied the motivations and the impact of foreign aid in the past decades. They have shown that aid is given for a combination of altruistic and self-interest motives, the weight between the two varying with the donor (Alesina and Dollar, 2000; Berthelemy, 2006). The altruistic motivation is related to a moral demand for redistribution when income gaps are important. In this context, foreign aid plays a similar role at the international level to progressive income taxes and social security institutions at the national level (Mosley, 1987). The selfish motivation for aid giving is the defense of the donors' own interests. These interests can be geopolitical (Alesina and Dollar, 2000; Stone, 2004; Dreher and Jensen, 2007), commercial (Fleck and Kilby, 2006; Villanger, 2006) or security related (Azam and Thelen, 2008). Lahiri et al. (2002) suggest another selfish trade related motive for aid: aid may reduce the recipient's optimal tariff. Then, tying the aid to a reduction in the recipient's tariff is Pareto improving. In contrast, the present paper suggests aid and the donor's tariff to be complementary for achieving some redistribution objective. As we shall see, tying the donor's tariff to the redistributive objective will then turn out to be Pareto improving. Following Azam and Laffont (2003), we assume a purely altruistic motivation for aid giving and we model foreign aid as a lump sum transfer that reduces the donor's revenues and increases those of the recipient by the same amount. In this paper, aid has no other impact than revenue redistribution from the donor to the recipient. In particular, it does not affect the recipient country's policies or growth rate. ${ }^{2}$

Resource economists have extensively studied the effects of nonrenewable resource taxation using dynamic models of resource depletion. ${ }^{3}$ Some scholars have focused on the redistributive impact of such taxes. The seminal paper by Bergstrom (1982) shows that, by taxing oil consumption, oil consuming countries can extract the entire oil rent from an oil producing country which is not using the resource itself: specifically, a constant ad valorem tax applied on the entire consumption of a costlessly extracted non-renewable resource induces the producer price (unit resource rent) to decrease while affecting neither the final price, nor the extracted quantity, at any date. The fixity of reserves gives consumption taxes a rent capturing dimension. Brander and Djajic (1983) show that this rent-extraction ability is mitigated if oil producers can use the resource themselves. Sinn (2008) makes it clear that the strong distributional effect

2 Many authors have tried to assess the impact of foreign aid on recipients' policies (Svensson, 2003; Easterly, 2005; Kilby, 2005) and growth (e.g., Burnside and Dollar, 2000; Hansen and Tarp, 2001; Easterly, 2003), but their findings are contradictory and there is currently no consensus on these questions.

${ }^{3}$ Examples of these analyses are Dasgupta and Heal (1979), Dasgupta et al. (1981) and Gaudet and Lasserre (1990). 
of oil taxation stems from the inelasticity of the resource supply induced by the exhaustibility constraint. This literature convincingly accounts for the gap between oil tax rates in oil importing and oil exporting regions and for the related rent capture by the former at the expense of the latter. This reasoning is robust to the introduction of environmental considerations. Amundsen and Schöb (1999) show that the incentives of oil importing countries to overtax oil use remain even if the resource use generates a flow of local pollution. Daubanes and Grimaud (2010) consider the case of a global stock of pollution. In this paper we abstract from pollution externalities generated by oil use in order to focus on the redistributive effect of taxes. Under some restrictions, Bergstrom's (1982) exposition highlights the isomorphism between the tax competition problem in a Hotelling model and in a static model where oil supply is perfectly inelastic. Following Bergstrom and the above conventional literature on the issue, we adopt a dynamic representation of oil extraction. ${ }^{4}$ On top of the inter-country heterogeneity in oil endowments examined by this environmental economics literature, we consider intra-country heterogeneity, i.e., the coexistence of rich resource holders and poor workers in the oil producing country. Moreover, we introduce international altruism and international redistribution instruments.

We formalize the interactions between a rich oil importing country (North) and a poor oil exporting country (South) using a dynamic general equilibrium model of resource depletion. The model is based on the following assumptions. Both countries produce a final good using labor and oil. The North is composed of high-productivity workers, while the South is composed of low-productivity workers and oil owners. Northern workers are altruistic towards southern workers. The policy instruments used by the authorities are oil taxes and foreign aid. We show that, without coordination, the northern government overtaxes oil, extracts rents from the southern oil owners and disburses foreign aid to the southern workers. After investigating the inefficiencies of this equilibrium, we show that a coordination mechanism that consists of a contract proposed by the northern authorities to the southern authorities can correct them. Through such a contract, northern authorities reduce taxes on oil from the South. This increases global output due to a more efficient allocation of oil. It also reduces northern fiscal revenues and leaves higher rents to the oil owners. As a counterpart, southern authorities redistribute the additional oil rents to the southern workers, thus reducing the need for foreign aid. We show that this redistribution scheme increases efficiency and is Pareto improving.

The rest of the paper is organized as follows. The model is presented in section 2. The general equilibrium for given policy instruments is solved in section 3 . The choice of oil tax rates and foreign aid by the governments

${ }^{4}$ Clearly, a static model would deliver the same message; however, to the extent that the distributional effects of taxes on endogenously extracted Hotelling resources arise from the long-run fixity of reserves but not from any assumption that short-run supply elasticity is zero, the static short-cut may be confusing about the real nature of those effects. It is on this ground that the literature has generally preferred the Hotelling representation. 
in the absence of coordination is examined in section 4 . The coordination mechanism is presented in section 5. Section 6 discusses a number of real world issues that are absent from our model. Finally, section 7 concludes.

\section{The model}

At each date $t \geq 0$, one final good is produced in both countries using labor and oil. The aggregate production functions are $^{5}$

$$
Y_{i}=\left(A_{i} L_{i}\right)^{1-\alpha} R_{i}^{\alpha}, 0<\alpha<1, i=N, S,
$$

where $A_{i}$ is an index of labor productivity, $L_{i}$ is the quantity of labor employed and $R_{i}$ is the quantity of oil used by the final sector firms of country $i$.

The index of labor productivity in the South is a constant fraction of that in the North. The growth rate of these indexes is exogenously given and constant: 6,7

$$
A_{N}=A, A_{S}=\varphi A \text {, with } 1 \geq \varphi>0, g_{A}=x \text { and } A(0)=A_{0}>0 \text {, given. }
$$

Oil is extracted at no cost from a finite initial stock $Q_{0}$ :

$$
\dot{Q}=-\left(R_{N}+R_{S}\right), Q(0)=Q_{0}>0, \text { given. }
$$

The northern population is composed of $L_{N}$ identical agents who are each endowed with one unit of labor. The southern population is composed of one group of $L_{S}$ workers (southern poor) who are each endowed with one unit of labor and one group of resource holders (southern rich) who own the oil stock $Q_{0}$. The size of the latter group is normalized to unity. The population of each group, and thus their labor quantity, is assumed to be constant over time; there is no inter-group mobility. ${ }^{8}$

${ }^{5}$ For the sake of notational simplicity, the time argument of each variable is dropped as long as this does not create ambiguity.

${ }^{6}$ We denote by $\dot{X}$ the derivative of any variable $\mathrm{X}$ with respect to time $\mathrm{t}$ and by $q_{x}=\frac{\dot{x}}{x}$ its growth rate over time.

7 The symmetric treatment of technical progress in both countries, reflected by the common growth rate $x$ of labor productivity indexes, can be seen as the counterpart of the assumption of stationarity in partial models. It avoids the issue of convergence between rich and poor countries, and its multiple facets. In a similar setting where growth is endogenously driven by research and development in the North, Daubanes and Grimaud's (2010) analysis shows that the assumption in (2) results from a diffusion process such that the time between an innovation in the North and its availability in the South is constant. The presence of a resourcerich, aid recipient country implies that, in a more realistic setting, account must be taken of resource curse and aid curse theories; such matters are beyond the scope of the present paper.

${ }^{8}$ Given the assumption in (2) that labor productivity indexes grow at a common rate, one could easily extend the model to exhibit a common growth rate of population sizes. 
All individuals are infinitely lived. The instantaneous consumption levels of the northern workers, the southern poor and the southern rich are respectively denoted by $C_{N}, C_{S P}$ and $C_{S R}$. The lifetime preferences of the representative agents of each group are represented by the utility functions:

$$
\begin{aligned}
U_{N} & =\int_{0}^{\infty}\left[L_{N} \ln \left(C_{N} / L_{N}\right)+\delta L_{S} \ln \left(C_{S P} / L_{S}\right)\right] e^{-\rho t} d t, \\
U_{S P} & =\int_{0}^{\infty}\left[L_{S} \ln \left(C_{S P} / L_{S}\right)\right] e^{-\rho t} d t, \\
U_{S R} & =\int_{0}^{\infty}\left[\ln \left(C_{S R}\right)\right] e^{-\rho t} d t,
\end{aligned}
$$

where $0<\rho<1$ is the intertemporal discount rate common to all groups and $\delta \geq 0$ is the altruism rate of the northern citizens towards the southern poor.

The global constraint on the use of the final good is

$$
Y_{N}+Y_{S}=C_{N}+C_{S P}+C_{S R} .
$$

There are world competitive markets for the final good and for oil, a world competitive financial market and local competitive labor markets. ${ }^{9}$ The final good price is normalized to unity and we denote by $p, r, w_{N}$ and $w_{S}$, the world oil price, the interest rate and the wages in the North and South respectively.

We assume that the northern government represents the northern citizens whereas the southern government only represents the resource holders, who constitute an elite close to the power. ${ }^{10}$ The governments seek to maximize the utility function of the group they represent.

The authorities can impose constant ${ }^{11}$ ad valorem taxes on the local use of oil. We denote the oil tax rates by $\theta_{i}>-1, i=N, S$. Then, the consumer

${ }^{9}$ In general, monopoly power is hardly exercised in non-renewable resource markets. Stiglitz (1976) shows that it cannot be exercised at all in a Hotelling model where demand is isoelastic, with constant demand elasticity, and where extraction costs are nil. The demand for the resource implied by the Cobb-Douglas production function (1) being isoelastic, as can be also seen from (8), Stiglitz's two conditions are satisfied in our analysis. Hence, our results are robust to the introduction of market power in the extraction sector.

10 The assumption that the developing country's authorities put a low weight on the welfare of the poor is common in the aid literature (e.g., Azam and Laffont, 2003; Hefeker and Michaelowa, 2005). For computational simplicity, we focus on the extreme case where this weight is zero, but our results would remain true as long as this weight is lower than that of the donor.

11 This assumption is made for simplicity. This follows Bergstrom (1982). His discussion on Nash equilibrium in varying strategies (p. 198) applies to our problem. Time-dependent tax rates would affect the oil extraction path, while the governments have no interest in distorting it. In the presence of pollution, optimal tax rates would be time varying. We refer to Daubanes and Grimaud (2010) for such a case. Their paper suggests that the introduction of pollution externalities would not change our results. 
oil prices are $\left(\theta_{N}+1\right) p$ in the North and $\left(\theta_{S}+1\right) p$ in the South. The fiscal revenues $\theta_{N} p R_{N}$ and $\theta_{S} p R_{S}$ are respectively redistributed to the northern citizens and to the southern resource holders.

Finally, we assume that the northern government can make a lump sum transfer $F(t) \geq 0$ of foreign aid to the southern poor. We assume that foreign aid grows at the same rate as the northern citizens' revenue. ${ }^{12}$

At date zero, the two governments set their policies non-cooperatively. Given these policies, the decentralized equilibrium realizes from date 0 onward, which determines the lifetime utility of the three groups. The problem must be solved by backward induction. First, we characterize the competitive general equilibrium for given oil tax rates and foreign aid. Second, we determine the Nash equilibrium policies.

\section{Competitive general equilibrium for given policies}

The final sector firms of country $i=N, S$ maximize their profits $\left(A_{i} L_{i}\right)^{1-\alpha} R_{i}^{\alpha}-w_{i} L_{i}-\left(\theta_{i}+1\right) p R_{i}$ with respect to the quantity of labor employed, $L_{i}$, and the quantity of oil used, $R_{i}$. In equilibrium, the firms equalize the marginal productivity of each input to its price:

$$
\begin{gathered}
\alpha\left(Y_{i} / R_{i}\right)=p\left(\theta_{i}+1\right), i=N, S, \\
(1-\alpha)\left(Y_{i} / L_{i}\right)=w_{i}, i=N, S .
\end{gathered}
$$

It is worth noting that a necessary condition for global optimality is $\theta_{N}=\theta_{S}$. If the tax rates differ across countries, the national marginal oil productivities are not equalized. Then world output could be increased by differently allocating oil between North and South.

The extraction sector firms maximize their profits $\int_{0}^{\infty} p(t) R(t) e^{-\int_{0}^{t} r(s) d s} d t$ with respect to the flows of extracted oil $R(t), t \geq 0$, under the exhaustibility constraint (3). In equilibrium, oil is managed as an asset and its extraction satisfies the standard Hotelling rule:

$$
\dot{p} / p=r
$$

The instantaneous budget constraints of the representative northern citizen, southern poor and southern rich are, respectively,

$$
\begin{gathered}
C_{N} / L_{N}+\dot{B}_{N} / L_{N}=w_{N}+r B_{N} / L_{N}+\theta_{N} p R_{N} / L_{N}-F / L_{N}, \\
C_{S P} / L_{S}+\dot{B}_{S P} / L_{S}=w_{S}+r B_{S P} / L_{S}+F / L_{S}, \\
C_{S R}+\dot{B}_{S R}=p\left(R_{N}+R_{S}\right)+r B_{N}+\theta_{S} p R_{S},
\end{gathered}
$$

where $B_{i}$ is group $i$ 's amount of financial assets, $i=N, S P, S R$.

12 This assumption is made for computational simplicity and is not restrictive. We could show that the optimal level of foreign aid is always a constant fraction of the northern citizens' income. 
Each household maximizes its utility $U_{i}, i=N, S P, S R$, under its budget constraint and the no-Ponzi-game necessary condition:

$$
\lim _{t \rightarrow \infty} B_{i}(t) e^{-\int_{0}^{t} r(s) d s}=0, i=N, S P, S R
$$

The first-order conditions of the households' maximization problem lead to the standard Ramsey-Keynes conditions:

$$
g_{C_{N}}=g_{C_{S P}}=g_{C_{S R}}=r-\rho .
$$

The financial market is in equilibrium at date 0 if $B_{N}(0)+B_{S P}(0)+$ $B_{S R}(0)=0$. Under this condition, the initial debt of each group is an arbitrary endowment. We assume that it is nil for all groups ${ }^{13}: B_{N}(0)=$ $B_{S P}(0)=B_{S R}(0)=0$.

Proposition 1. The following properties are satisfied in equilibrium.

1. National production levels $Y_{N}$ and $Y_{S}$, as well as consumption levels of the three groups $C_{N}, C_{S P}$ and $C_{S R}$, grow at the same rate $g=(1-$ $\alpha) x-\alpha \rho$.

2. The ratio of production levels $Y_{N} / Y_{S}$ is a decreasing function of the ratio of oil tax rates $\left(\theta_{N}+1\right) /\left(\theta_{S}+1\right)$.

3. For given production levels $Y_{N}$ and $Y_{S}$ and a given level of foreign aid $F, \theta_{N}$ has a positive effect on $C_{N}$, a negative effect on $C_{S R}$ and no effect on $C_{S P}$, whereas $\theta_{S}$ has no effect on the consumption levels.

\section{Proof. See the online Appendix.}

According to the first property, the growth rate in the two countries stems from exogenous technical progress and resource depletion but, under our assumptions, is constant, independent of oil tax rates and of the level of foreign aid. This equilibrium property simplifies our analysis a good deal, since it reduces governments' optimization problems to the maximization of utilities at date $0 .{ }^{14}$

The second and third properties disentangle two effects of oil tax rates on the revenues of the three groups: a location effect on national production levels and a pure distributional effect on consumption levels. ${ }^{15}$

The location effect is that of the relative oil tax rates on the repartition of the final good production between North and South. If oil taxes increase in

13 This is done for notational simplicity. Our results are robust to a different assumption on the level of initial debt.

${ }^{14}$ In a context of non-regular growth, as in Bretschger and Pittel (2008), our analysis would not have been feasible.

15 The distributional effects of non-renewable resources taxation have been studied by Bergstrom (1982), Liski and Tahvonen (2004), Sinn (2008) and Daubanes and Grimaud (2010), among others. In particular, the latter paper analytically identifies the locational and distributional effects of national resource taxes. 
the North, northern firms become less competitive since one of their inputs becomes relatively more expensive. Then northern firms will use a lower share of oil extracted at each date. Since the other input, labor, is immobile, a decrease in oil use implies a lower final good production. Therefore, a unilateral increase in $\theta_{N}$ decreases $Y_{N}$ and increases $Y_{S}$, with the opposite being true for $\theta_{S}$.

The distributional effect is that of the absolute oil tax rates on the repartition of oil rents between fiscal authorities and resource holders. Oil taxes decrease the equilibrium price of oil, transferring some of resource holders' rents to the fiscal authorities. This transfer positively affects the consumption level of northern households, who benefit from the northern fiscal revenues, and negatively affects the consumption level of southern oil owners, who lose rents.

Precisely, one can see from the first-order conditions (8) that the total payment for oil by the final sector firms, $p\left(\theta_{N}+1\right) R_{N}+p\left(\theta_{S}+1\right) R_{S}$, is equal to $\alpha Y_{N}+\alpha Y_{S}$. This payment is composed of three parts: $p\left(R_{N}+\right.$ $\left.R_{S}\right)=\alpha\left(Y_{N} /\left(\theta_{N}+1\right)+Y_{S} /\left(\theta_{S}+1\right)\right)$ is the resource holders' oil revenue; $\theta_{N} p R_{N}=\alpha \theta_{N} Y_{N} /\left(\theta_{N}+1\right)$ is the northern fiscal revenue, redistributed to the northern households; and $\theta_{S} p R_{S}=\alpha \theta_{S} Y_{S} /\left(\theta_{S}+1\right)$ is the southern fiscal revenue, redistributed to the resource holders. The resource holders' net revenue is then equal to $\alpha Y_{N} /\left(\theta_{N}+1\right)+\alpha Y_{S}$. From these expressions we can see that, for given production levels $Y_{N}$ and $Y_{S}$, the northern oil tax $\theta_{N}$ decreases resource holders' net revenue and increases northern households' fiscal revenue. This is a pure distributional effect. Moreover, we can see that $\theta_{S}$ does not influence resource holders' revenues. The reason for this is that $\theta_{S}$ shifts part of the oil rents into southern fiscal revenues, both of which are earned by the resource holders. Their total revenue is therefore not affected by this tax.

Overall, the northern tax rate $\theta_{N}$ has a negative effect on northern households' labor earnings since it decreases northern production $Y_{N}$, and a positive effect on their fiscal earnings since it increases northern fiscal revenues, $\alpha \theta_{N} Y_{N} /\left(\theta_{N}+1\right)$. The northern government will face this tradeoff when choosing the tax rate. Moreover, the altruistic northern government will have to take into account the positive effect of $\theta_{N}$ on the southern workers' labor earnings, but not its negative effect on the resource holders' revenues.

Let us denote by $C_{N}\left(\theta_{N}, \theta_{S}, F\right)(t), C_{S P}\left(\theta_{N}, \theta_{S}, F\right)(t)$ and $C_{S R}\left(\theta_{N}, \theta_{S}\right)(t)$ the equilibrium consumption levels of the three groups at date $t$ as functions of the tax rates and of the level of foreign aid. Their expressions are computed in the online Appendix, available at http://journals.cambridge.org/EDE. The following section examines the choice of instruments by the governments at the Nash equilibrium.

\section{Equilibrium policies}

In this section we assume that the northern and southern governments set their policies non-cooperatively.

The northern government chooses the oil tax rate $\theta_{N}$ and the level of foreign aid $F(t) \geq 0$ that maximize northern agents' lifetime utility, 
taking as given the equilibrium consumption functions $C_{N}\left(\theta_{N}, \theta_{S}, F\right)(t)$ and $C_{S P}\left(\theta_{N}, \theta_{S}, F\right)(t)$ and the southern government's strategy $\theta_{S}$ :

$$
\begin{aligned}
\max _{\theta_{N},\{F(t)\}_{t \geq 0}} \int_{0}^{\infty} & {\left[L_{N} \ln \left(\frac{C_{N}\left(\theta_{N}, \theta_{S}, F\right)(t)}{L_{N}}\right)+\delta L_{S} \ln \left(\frac{C_{S P}\left(\theta_{N}, \theta_{S}, F\right)(t)}{L_{S}}\right)\right] } \\
& \times e^{-\rho t} d t
\end{aligned}
$$

s.t. $\forall t, F(t) \geq 0$.

The southern government chooses the tax rate $\theta_{S}$ which maximizes the resource holders' lifetime utility, taking as given the equilibrium consumption function $C_{S R}\left(\theta_{N}, \theta_{S}\right)(t)$ and the northern government's strategy $\theta_{N}$ :

$$
\max _{\theta_{S}} \int_{0}^{\infty} \ln \left(C_{S R}\left(\theta_{N}, \theta_{S}\right)(t)\right) e^{-\rho t} d t .
$$

From Proposition 1, $C_{N}\left(\theta_{N}, \theta_{S}, F\right)(t), C_{S P}\left(\theta_{N}, \theta_{S}, F\right)(t)$ and $C_{S R}\left(\theta_{N}, \theta_{S}\right)$ ( $t$ ) grow at the same rate, which does not depend on governments' policies. Therefore, governments' optimization problems reduce to the maximization of date 0 utilities (see online Appendix for formal proof).

Let us denote by $\theta_{N}^{e}, \theta_{S}^{e}$ and $F^{e}(t)$ the Nash equilibrium strategies.

Proposition 2. Equilibrium policies satisfy the following properties:

1. The oil tax rate is strictly positive in the North and nil in the South: $\theta_{N}^{e}>\theta_{S}^{e}=0$.

2. Foreign aid is positive if the North is sufficiently altruistic: $F^{e}(t)>0$ if $\delta>\underline{\delta}$.

Proof. See the online Appendix.

Proposition 2 shows that, in the absence of coordination mechanisms, the two governments set different oil tax rates. This is due to the asymmetric oil endowments of the groups that they represent.

The southern government has no incentives to tax oil. From Proposition 1, for given production levels $Y_{N}$ and $Y_{S}, \theta_{S}$ is neutral to the consumption level of the oil owners, $C_{S R}\left(\theta_{N}, \theta_{S}\right)(t)$. The fiscal revenues that could be collected with a positive tax rate and redistributed to the resource holders are exactly equal to the loss in oil revenue that this tax would cause them. Moreover, we have seen that an increase in $\theta_{S}$ would shift some final good production to the North, increasing $Y_{N}$ with respect to $Y_{S}$. This would increase the share of oil consumed by the northern firms, on which the South levies no taxes. Taxing oil would therefore induce a net loss for the resource holders. Hence, $\theta_{S}^{e}=0$ is a dominant strategy for the southern government. This is true for any northern strategy and will thus be valid all along in the sequel. This is a noticeable difference from studies which assume the southern government to maximize the entire surplus of 
southern residents, including workers, and where the optimal tax for the resource exporting country is found to be negative (e.g., Bergstrom, 1982). ${ }^{16}$

The northern government can use the oil tax to capture rents from the resource holders and transfer them to the northern citizens. From Proposition 1, for given production levels $Y_{N}$ and $Y_{S}, \theta_{N}$ increases $C_{N}\left(\theta_{N}, \theta_{S}, F\right)(t)$ and decreases $C_{S R}\left(\theta_{N}, \theta_{S}\right)(t)$. As northern households do not internalize the negative effect of $\theta_{N}$ on resource holders' consumption levels, they would like to set the highest possible tax rate. However, we have also seen in Proposition 1 that $\theta_{N}$ decreases northern households' labor earnings because it shifts some final good production to the South. This limits the northern ability to capture oil rents through oil taxation. Therefore, $\theta_{N}^{e}$ is positive but not infinite.

The northern government can also use the oil tax to increase southern workers' consumption levels, since by shifting some productive activities to the South, $\theta_{N}$ increases their labor earnings. This redistribution possibility increases the optimal tax rate for the altruistic North.

In fact, the altruistic northern government can use two redistribution instruments to increase southern workers' consumption levels. One the one hand, it can use foreign aid $F$, which is a lump sum transfer. This transfer decreases northern households' consumption and increases that of the southern workers by the same amount. On the other hand the North can use the oil $\operatorname{tax} \theta_{N}$, which allows a non-lump sum transfer to the southern poor. An increase in $\theta_{N}$ increases southern workers' labor earnings and decreases those of the northern workers, but not necessarily by the same amount. This redistribution mechanism modifies the marginal productivities of oil in the North and South, and is not efficiency neutral.

Figure 1 illustrates how the rate of altruism $\delta$ affects the choice of these two redistribution mechanisms. The tax rate $\theta_{0}>0$ is the one that maximizes northern households' total revenue. This tax rate is implemented when the North is not altruistic, i.e., when $\delta=0$. The optimal northern tax rate $\theta_{N}^{e}$ increases with the altruism rate up to $\underline{\theta}$, which is implemented for an altruism level $\delta=\underline{\delta}$. For $\delta \leq \underline{\delta}$, foreign aid is nil and redistribution is done through oil taxation, which is the cheapest redistribution instrument on this segment. For $\delta>\underline{\delta}, \theta_{N}^{e}$ remains equal to $\underline{\theta}$, and $F^{e}$ becomes positive and strictly increasing with $\delta$. On this segment, foreign aid is the cheapest redistribution mechanism.

It is worth noting that redistributing revenues to the South by decreasing its own competitiveness with high oil taxes may not be very attractive in a more-than-two-country framework. In that case, high oil taxes in the North would favor all other countries and not exclusively the targeted group of poor. That is why, although this effect arises in our model, we will focus on foreign aid as the main redistribution scheme, i.e., on the cases where $\delta \geq \underline{\delta}, \theta_{N}^{e}=\underline{\theta}$ and $F^{e}>0$.

We show in the online Appendix that $\underline{\theta}$ is defined by $\underline{\theta} \equiv$ $\operatorname{argmax}_{\theta_{N}}\left[C_{N}\left(\theta_{N}, 0,0\right)+C_{S P}\left(\theta_{N}, 0,0\right)\right]$ and $\underline{\delta}$ is defined by $\underline{\delta} \equiv \frac{C_{S P}(\underline{\theta}, 0,0) / L_{S}}{C_{N}(\theta, 0,0) / L_{N}}$

${ }^{16}$ In this case, the gap between the northern and southern tax rates would imply a global inefficiency in the global allocation of the resource of the same nature. 

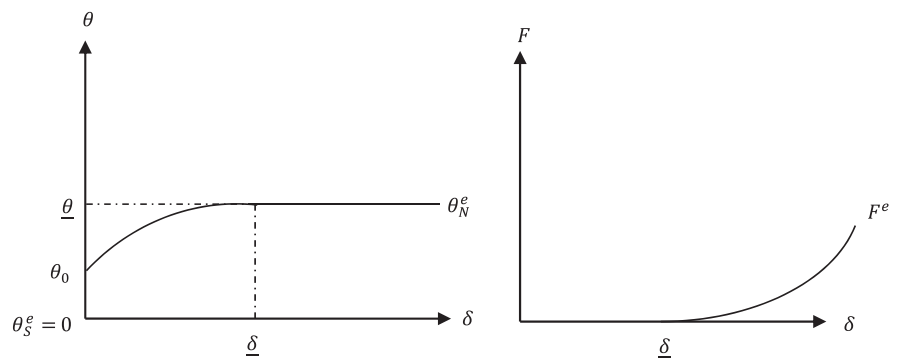

Figure 1. Equilibrium policies

When $\delta>\underline{\delta}$, the equilibrium level of foreign aid splits the total revenue of the northern workers and the southern workers, $C_{N}(\underline{\theta}, 0,0)+C_{S P}(\underline{\theta}, 0,0)$, according to the weight of each group in the northern utility function:

$$
\begin{aligned}
C_{N}\left(\underline{\theta}, 0, F^{e}\right) & =\frac{L_{N}}{L_{N}+\delta L_{S}}\left[C_{N}(\underline{\theta}, 0,0)+C_{S P}(\underline{\theta}, 0,0)\right], \\
C_{S P}\left(\underline{\theta}, 0, F^{e}\right) & =\frac{\delta L_{N}}{L_{N}+\delta L_{S}}\left[C_{N}(\underline{\theta}, 0,0)+C_{S P}(\underline{\theta}, 0,0)\right] .
\end{aligned}
$$

Figure 1 also illustrates the gap between $\theta_{N}^{e}$ and $\theta_{S}^{e}$. This gap in taxation leads to different consumer prices of oil in the North and South: $\left(\theta_{N}^{e}+1\right) p^{e}>\left(\theta_{S}^{e}+1\right) p^{e}$. This implies that the national marginal productivities of oil are not equalized. Global output could be increased if a larger share of oil were used in the North, where its marginal productivity is higher. The equilibrium allocation of oil between North and South is therefore inefficient.

Our model features the two opposite revenue transfers described in the introduction between developed oil consuming countries and developing oil producing countries. The North gives foreign aid to the southern poor and captures oil rents from the southern rich. Oil taxes are strictly higher in the North, leading to an inefficient allocation of oil between northern and southern firms. The following section proposes a policy coordination mechanism aimed at reducing this inefficiency.

\section{Equilibrium policies with the coordination mechanism}

The inefficiency of the equilibrium described in the previous section stems from the incentives of the North to overtax the resource in order to capture oil rents from the resource holders. One way of correcting this inefficiency is to reduce the incentives to capture those rents.

A reduction of the northern oil tax rate would lead to a more efficient allocation of oil and increase global production, but the resulting revenue increase would unevenly benefit the three groups. Resource holders' rents would increase while the total revenue of the northern residents and the southern poor would decrease. As the North does not internalize resource holders' consumption, it has no incentives to lower its tax. However, if 
some of the resulting oil rents were redistributed to the poor population for which the North is altruistic, it might be willing to lower the tax. This is the basis of our coordination mechanism.

Consider the following contract proposed by the northern authorities to the southern authorities. The contract specifies the northern tax rate $\theta_{N}$ and the amount of national aid $I(t) \geq 0$ to be transferred from the resource holders to the southern poor.

Southern authorities will accept the contract if and only if it increases resource holders' utility. ${ }^{17}$ Moreover, the result that a zero tax is dominant from the southern government's perspective still applies, so that $\theta_{S}^{c}=0$ holds. Hence, their participation constraint is

$$
\int_{0}^{\infty} \ln \left(C_{S R}\left(\theta_{N}, 0\right)(t)-I(t)\right) e^{-\rho t} d t \geq \int_{0}^{\infty} \ln \left(C_{S R}\left(\theta_{N}^{e}, 0\right)(t)\right) e^{-\rho t} d t .
$$

The optimal contract for the northern government solves

$$
\begin{gathered}
\max _{\theta_{N},\{I(t)\}_{t \geq 0},\{F(t)\}_{t \geq 0}} \int_{0}^{\infty} L_{N} \ln \left(\frac{C_{N}\left(\theta_{N}, 0, F\right)(t)}{L_{N}}\right) \\
+\delta L_{S} \ln \left(\frac{C_{S P}\left(\theta_{N}, 0, F\right)(t)+I(t)}{L_{S}}\right) e^{-\rho t} d t
\end{gathered}
$$$$
\text { s.t. (17) and, } \forall t, F(t) \geq 0, I(t) \geq 0 \text {. }
$$

As $I(t)$ enters the North's utility function with a positive sign, the South's participation constraint will be binding. This implies that all the oil rents resulting from the decrease in the northern oil tax will be redistributed to the poor: $\forall t, I(t)=C_{S R}\left(\theta_{N}, 0\right)(t)-C_{S R}\left(\theta_{N}^{e}, 0\right)(t)$. Thus, $I(t)$ grows at the same rate as all the other variables and the North's optimization problem is reduced again to the date zero utility maximization.

We denote the optimal contract by $\left(\theta_{N}^{c},\left(I^{c}(t)\right)_{t \geq 0}\right)$ and the optimal level of foreign aid when the contract is used by $F^{c}(t)$.

Proposition 3. Equilibrium policies with the coordination mechanism satisfy the following properties:

1. Coordination improves global efficiency: $\theta_{N}^{c}<\theta_{N}^{e}$ and $\theta_{N}^{c}=0$ if $\delta \geq \underline{\underline{\delta}}$.

2. Internal redistribution is always positive and foreign aid is positive if the North is sufficiently altruistic: $I^{c}>0$, and $F^{c}>0$ if $\delta>\underline{\delta}$.

\section{Proof. See the online Appendix.}

Proposition 3 shows that the constraint $I(t) \geq 0$ (which is equivalent to $\theta_{N}^{c} \leq \theta_{N}^{e}$, since $C_{S R}\left(\theta_{N}, 0\right)(t)$ is decreasing in $\left.\theta_{N}\right)$ is never binding. This

17 Although it is more reasonable to assume that southern authorities accept the contract only if it strictly increases their utility, we will follow the convention that the participation constraint extends to equality. Hence, when this constraint will be binding, it should perhaps be interpreted as almost binding. 

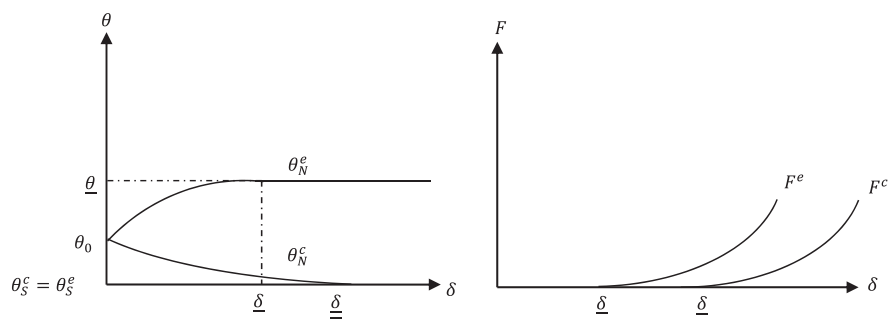

Figure 2. Equilibrium policies with the coordination mechanism

means that the North can always obtain a strictly higher payoff by using the contractual coordination instrument. The reason for this is the following. Without the contract, the North captures some of resource holders' rents by overtaxing the resource at the expense of its own competitiveness, while helping the southern poor with lump sum foreign aid. By transferring oil rents to the southern poor, the contract allows the altruistic North to benefit from oil rents, while increasing its own competitiveness. It is a more efficient revenue redistribution scheme.

At the altruism threshold rate $\underline{\delta}$, the optimal contractual tax rate in the North becomes nil and the possibility of revenue redistribution through the contract is exhausted. If northern altruism is greater than this threshold, foreign aid is used to complement the redistributive role of the contract.

We show in the online Appendix that $\underline{\underline{\delta}}$ is given by $\underline{\underline{\delta}}=$ $\frac{\left[C_{s p}(0,0,0)+C_{S R}(0,0)-C_{S R}(\underline{\theta}, 0)\right] / L_{S}}{C_{N}(0,0,0) / L_{N}}$. When $\delta>\underline{\underline{\delta}}$, the level of foreign aid $F^{c}$ splits the net revenue of the northern workers and the southern poor, $C_{N}(0,0,0)+C_{S P}(0,0,0)+\left[C_{S R}(0,0)-C_{S R}(\underline{\theta}, 0)\right.$, according to the weight of each group in the northern citizen's utility function:

$$
\begin{aligned}
& C_{N}\left(0,0, F^{c}\right) \\
& \quad=\frac{L_{N}}{L_{N}+\delta L_{S}}\left[C_{N}(0,0,0)+C_{S P}(0,0,0)+C_{S R}(0,0)-C_{S R}(\underline{\theta}, 0)\right], \\
& C_{S P}\left(0,0, F^{c}\right) \\
& \quad=\frac{\delta L_{S}}{L_{N}+\delta L_{S}}\left[C_{N}(0,0,0)+C_{S P}(0,0,0)+C_{S R}(0,0)-C_{S R}(\underline{\theta}, 0)\right] .
\end{aligned}
$$

Figure 2 illustrates the North's choice of these instruments in the case where $\underline{\delta}<\underline{\delta}$.

Proposition 3 shows that the coordination instrument restores global efficiency, i.e. $\theta_{N}^{c}=\theta_{S}^{c}$ when the North is sufficiently altruistic, i.e., when $\delta>\underline{\delta}$.

It is worth noting that the complete restoration of efficiency stems from the use of an additional instrument by a strategic agent (the northern government), who is not benevolent - in particular, who does not care about 
the welfare of the oil owners. This result is surprising ${ }^{18}$ and it deserves some particular attention. It can be explained in the following way. The contract allows the northern government to manipulate the split of world output between the different groups. We show in the online Appendix that when the contract is used by a sufficiently altruistic North, its optimization problem amounts to maximizing global output $Y$ minus a fixed rent that cannot be captured, which is oil owners' consumption in the absence of the contract, $C_{S R}(\underline{\theta}, 0)$. Since the North is led to maximize world output minus a fixed quantity, it is not willing to introduce distortional taxes that would decrease world output.

Beyond the improvement of global efficiency shown in Proposition 3, let us examine the effects of the contract on the welfare of each group. The welfare of the North is obviously improved by the availability of an additional instrument. ${ }^{19}$ Resource holders' welfare is unchanged as their participation constraint is binding. The contract has three effects on the consumption of the southern poor. First, it decreases their wages because some of the final good production moves to the North. Second, it decreases the amount of foreign aid they receive. Third, it introduces a positive amount of national aid. Proposition 4 shows that the overall effect on their revenue is always positive.

Proposition 4. The introduction of the coordination mechanism leads to a Pareto improvement of the equilibrium allocation.

\section{Proof. See the online Appendix.}

The coordination mechanism suggested in this paper improves global efficiency and welfare. It offers a more efficient redistribution scheme to help the poor living in oil exporting countries. Although this solution has good properties, it relies on a theoretical model that abstracts from some real world issues which are discussed in the following section.

\section{Discussion}

The above analysis has shown that the interactions between rich oil consuming countries and poor oil producing countries via oil taxation and foreign aid policies results in an inefficiency of the oil allocation. This inefficiency arises because the possibility of capturing oil holders' rents by

18 A known example in which a strategic agent is led to maximize total welfare is that of a monopoly perfectly discriminating between consumers, since in that case the monopoly is able to capture the entire surplus. In our case, however, the strategic northern government is not able to capture the entire surplus but only a part of it.

19 The effect of the contract on the northern government's budget cannot be established. On the one hand, the tax decrease may induce fiscal revenues to decrease. On the other hand, the aid decrease entails a reduction in expenditures. In our setting, the counterpart of the net budgetary effects is the adjustment of lump sum transfers so that the government's budget constraint is always satisfied. 
northern oil taxation induces the northern government to overtax oil; this tendency is magnified by the northern altruism towards the poor in the oil producing region, even when oil taxation coexists with foreign aid transfers in favor of the latter.

The possibility of correcting this inefficiency through the coordination mechanism described in section 5 is theoretically interesting for two reasons. First, it highlights that the source of the economic problem is a lack of coordination between the two regions. Second, while our abstract setting focuses on the main features of the problem, the corrective contract on the North's initiative may serve as a basis for more realistic proposals.

In the current context, no mention of oil taxes can avoid a discussion of their environmental dimension. This will be done briefly below; as we will argue, the mechanism of the contract of section 5 must survive environmental considerations absent from the setting of this paper. Some other real world issues absent from our theoretical model are worth discussing: credibility of the redistribution of oil rents by the southern government, recipient targeting, donor coordination, transparency, transfer visibility and transaction costs. This will be done thereafter.

For reasons that were unrelated to environmental concerns, ${ }^{20}$ the US Congressional office suggested in 1986 the idea of lowering the tariff on oil imported from some low-income countries. In that proposal, there was no condition on the redistribution of the resulting extra-rents within these countries. More recently, Sala-i-Martin and Subramanian (2003) suggested that oil revenues in Nigeria be equally shared among the whole population, but without specifying any compensation for the elite monopolizing the oil rents. The mechanism of section 5 combines the ideas of lowering oil taxes with a better redistribution of the oil rents, but it further takes into account the interests of all groups involved, thus introducing the necessity of political feasibility.

Our theoretical analysis also abstracts from global pollution externalities caused by oil consumption. Would our coordination mechanism still be welfare improving if environmental concerns are taken into account? First, in the presence of a global quantity based environmental regulation, to which industrialized countries seem to give priority, taxes should not pursue any environmental objective and our analysis would carry over without any further adjustment.

Otherwise, were oil taxes set in order to pursue this environmental objective, the same forces as in the present paper would be at work: oil-poor countries would still tend to tax at higher levels than oil-rich countries. This is the message delivered by Amundsen and Schöb (1999) and Daubanes and Grimaud (2010). As emphasized in the latter paper, in a Hotelling model the environmental effect of oil taxes depends on their dynamic pattern, while global efficiency requires homogeneous after-tax price levels. A globally efficient allocation of polluting inputs is always a prerequisite to environmental efficiency. More generally, as long as marginal damages

20 The objective of that proposal was to avoid poor countries' inability to meet their debt payments. 
from oil use are independent of where oil is consumed, the price unicity principle must hold. Thus, overtaxation by northern countries, for whatever reasons, ${ }^{21}$ can still be corrected by the contractual mechanism at the root of section 5 . Were the optimal level of oil taxation strictly positive, ${ }^{22}$ the mechanism should target it, instead of a zero level as in section 5 . The intuition survives as long as the gap between regions' taxes offers efficiency gain from tax convergence. This may not necessarily imply the convergence of northern taxation to the southern level. Whether a contractual solution of this kind can induce southern regions, if taxing at suboptimal levels, to increase their taxes, is a more intricate question that we leave unexplored. Efficiency gains from tax convergence, again, leave opportunities to provide such incentives, though.

The theoretical interest of contractual mechanisms should not hide the practical difficulties of such solutions. In the following paragraphs, we discuss critical assumptions of our analysis and argue that coordination mechanisms of the kind introduced in section 5 are not devoid of practical relevance.

Our framework assumes that the additional oil rents resulting from lower taxes in the North will effectively be redistributed to the poor population in the oil exporting country. This is a strong assumption given the poor institutions and non-representative governments of many oil exporting countries. In a dynamic contract setting, this commitment problem could be overcome given the repeated nature of donor-recipient interactions. If industrialized countries lowered oil tax rates and observed that the resulting oil revenues in the South did not benefit the poor population, they could always go back to the non-coordinated equilibrium policies. This credible threat may be sufficient to induce southern authorities to respect their redistribution commitments.

There is another consideration. Observability is always an issue, not only under contractual schemes, but also, and in much the same way, under any form of foreign aid destined to a particular group. Hence, the efficiency gains from coordination are irrespective of the degree of observability.

An important issue absent from our two-country model is the targeting of recipients. While foreign aid can easily be targeted to a recipient, lowering oil taxes in a world with several oil exporting countries would enrich all such countries and not only those that the donor is willing to favor. Targeting low-income countries could be implemented by lowering tariffs on oil originating from those countries exclusively.

Symmetrically, our one-donor-one-recipient model focuses on the necessity of coordination between donor and recipient policies. However, coordination between different donors is not less important. A unilateral

${ }^{21}$ Daubanes and Lasserre (2011) show that a government in need of raising commodity tax revenues must target non-renewable resources as a priority.

22 While absent in Daubanes and Grimaud's (2010) Hotelling analysis, endogeneity of reserves would make the level of taxation relevant for environmental policy as this level would discourage extraction. 
decrease in oil taxes by one industrialized country may have little effect on the equilibrium oil price and it may create oil price gaps with other industrialized countries, leading to other distortions. The issue of donor coordination deserves more attention in future research.

In this paper, taxes and aid are collected and redistributed at no cost. In reality, these transfers entail non-negligible costs of public funds. While a second-best setting would blur the main message that coordination can improve efficiency, it is worth noting the following. If costs of public funds increased with the amount of taxes collected and redistributed, then contractual coordination mechanisms, by reducing those amounts, would further have the benefit of reducing transaction costs.

Relatedly, since policy coordination also reduces foreign aid transfers, it makes international redistribution less visible. Visibility may matter, especially if the motivation of foreign aid is not purely altruistic. To overcome this problem, the amounts indirectly transferred through contractual mechanisms such as the one suggested here could be included in some extended definition of foreign aid.

\section{Conclusion}

This paper points out the inefficiency that arises when oil importing donor countries (North) and oil exporting recipient countries (South) interact through oil taxation and foreign aid policies. In the absence of coordination, the North overtaxes oil use with a view to capturing rents from the oil owners in the South. The northern tendency to overtax oil is magnified by its willingness to redistribute oil rents to the poor population in the South via foreign aid. The gap between oil taxes in the North and in the South entails a global distortion of the allocation of oil.

We show how a well-designed policy coordination mechanism reduces this inefficiency. It consists of a contract proposed by the northern authorities to the southern authorities, by which the former lower oil taxes and the latter redistribute the resulting oil rents to the poor. This coordination mechanism increases global output by reducing distortions in the allocation of oil. A larger share of oil is used by the final sector firms in the North, where its productivity is higher. The opposite revenue transfers between North and South are reduced, while revenue redistribution from southern rich to southern poor is increased. Northern workers earn higher direct revenues due to the improved competitiveness of northern firms; they earn lower fiscal revenues from oil taxation and they redistribute less foreign aid to the southern workers. Oil owners earn higher rents, but they redistribute them to the southern poor. Southern poor earn lower direct revenues and receive less foreign aid, but they benefit more from the oil rents. We show that the introduction of such a coordination mechanism is Pareto improving.

By drawing attention to the efficiency gains of coordination between oil importing donor countries and oil exporting recipient countries, this paper is intended to inspire future research on policy coordination mechanisms. In particular, it would be interesting, both from a theoretical and a policy perspective, to further examine the benefits of such coordination schemes 
when account is taken of oil polluting character as well as of heterogeneity among donors and among recipients, of asymmetries of information and of commitment problems.

\section{References}

Alesina, A. and D. Dollar (2000), 'Who gives foreign aid to whom and why?', Journal of Economic Growth 5: 33-63.

Amundsen, E.S. and R. Schöb (1999), 'Environmental taxes on exhaustible resources', European Journal of Political Economy 15: 311-329.

Azam, J.-P. and J.-J. Laffont (2003), 'Contracting for aid', Journal of Development Economics 70: 25-58.

Azam, J.-P. and V. Thelen (2008), 'The roles of foreign aid and education in the war on terror', Public Choice 135: 375-397.

Bacon, R. (2001), 'Petroleum taxes: trends in fuel taxes (and subsidies) and the implications', Public Policy for the Private Sector Note 240, World Bank, Washington, DC.

Bergstrom, T.C. (1982), 'On capturing oil rents with a national excise tax', American Economic Review 72: 194-201.

Berthelemy, J.-C. (2006), 'Bilateral donors' interest vs. recipients' development motives in aid allocation: do all donors behave the same?', Review of Development Economics 10: 179-194.

Brander, J. and S. Djajic (1983), 'Rent-extracting tariffs and the management of exhaustible resources', Canadian Journal of Economics 16: 288-298.

Bretschger, L. and K. Pittel (2008), 'From time zero to infinity: transitional and long-run dynamics in capital-resource economies', Environment and Development Economics 13: 673-689.

Burnside, C. and D. Dollar (2000), 'Aid, policies and growth', American Economic Review 90: 847-868.

Dasgupta, P.S. and G.M. Heal (1979), Economic Theory and Exhaustible Resources, Cambridge: Cambridge University Press.

Dasgupta, P.S., G.M. Heal, and J.E. Stiglitz (1981), 'The taxation of exhaustible resources', Working Paper No. 0436, NBER, Cambridge, MA.

Daubanes, J. and A. Grimaud (2010), 'Taxation of a polluting non-renewable resource in the heterogeneous world', Environmental and Resource Economics 47: $567-588$.

Daubanes, J. and P. Lasserre (2011), 'Optimum commodity taxation with a nonrenewable resource', Working Paper No. 2011s-05, CIRANO, Montréal.

Dreher, A. and N. Jensen (2007), 'Independent actor or agent? An empirical analysis of the impact of US interests on IMF conditions', Journal of Law $\mathcal{E}$ Economics 90: 105-124.

Easterly, W. (2003), 'Can foreign aid buy growth?', Journal of Economic Perspectives 17: $23-48$.

Easterly, W. (2005), 'What did structural adjustment adjust? The association of policies and growth with repeated IMF and World Bank adjustment loans', Journal of Development Economics 76: 1-22.

Fleck, R.K. and C. Kilby (2006), 'World Bank independence: a model and statistical analysis of US influence', Review of Development Economics 10: 224-240.

Gaudet, G. and P. Lasserre (1990), 'Dynamiques comparées des effets de la taxation minière', L'Actualité Economique 66: 467-497.

Hansen, H. and F. Tarp (2001), 'Aid and growth regressions', Journal of Development Economics 62: 547-570. 
Hefeker, C. and K. Michaelowa (2005), 'Can process conditionality enhance aid effectiveness? The role of bureaucratic interest and public pressure', Public Choice 122: 159-175.

International Energy Agency (2001), Dealing with Climate Change: Policies \& Measures in IEA Member Countries, Paris: OECD Publishing.

Kilby, C. (2005), 'World Bank lending and regulation', Economic Systems 29: 384-407.

Lahiri, S., P. Raimondos-Møller, K.-Y. Wong, and A.D. Woodland (2002), ‘Optimal foreign aid and tariffs', Journal of Development Economics 67: 79-99.

Liski, M. and O. Tahvonen (2004), 'Can carbon tax eat OPEC's rents?', Journal of Environmental Economics and Management 47: 1-12.

Mosley, P. (1987), Overseas Aid: Its Defense and Reform, Brighton: Wheatsheaf Books.

OECD (2010), 'Aggregate Aid Statistics: ODA by recipient by country', OECD International Development Statistics (database); doi:10.1787/data-00064-en.

OPEC (2008), Who Gets What From Imported Oil?, Vienna: OPEC Research Division.

PennWell Corporation (2004), Oil \& Gas Journal 112(47).

Sala-i-Martin, X.X. and A. Subramanian (2003), 'Addressing the natural resource curse', IMF Working Paper No. 03/139, International Monetary Fund, Washington, DC.

Sinn, H.-W. (2008), 'Public policies against global warming: a supply side approach', International Tax and Public Finance 15: 360-394.

Stiglitz, J.E. (1976), 'Monopoly and the rate of extraction of exhaustible resources', American Economic Review 66: 655-661.

Stone, R. (2004), 'The political economy of IMF lending in Africa', American Political Science Review 98: 577-591.

Svensson, J. (2003), ‘Why conditional aid does not work and what can be done about it?', Journal of Development Economics 70: 381-402.

Villanger, E. (2006), 'Company interests and foreign aid policy: playing donors off against one another', European Economic Review 50: 533-545.

World Bank (2010), World Development Indicators, Washington, DC: World Bank. 